\title{
Copyright Management and its Effect on the Sampling Practice of UK Dance Music Producers
}

\author{
Justin Morey \\ Leeds Metropolitan University \\ j.morey@leedsmet.ac.uk
}

\begin{abstract}
This article draws on qualitative data gained from interviews with a number of established UK dance music producers. Consideration is given to how sampling practice developed in the UK, including the influence of American hip-hop pioneers, the ethical rules that the producers apply to their use of samples, and the extent to which their compositional methods and creative choices have adapted in response to increasingly exacting copyright enforcement. It is argued that copyright and its application is one of a number of affordances and constraints, be they technological, industrial, sociocultural or legal that help to shape the creative practice of these producers.
\end{abstract}

Keywords: Digital sampling, creative practice, legal framework, music industry, technology.

\section{Introduction}

The introduction of affordable digital sampling technology in the late 1980s had a significant effect on the sound of hip-hop produced in the USA and on its global reach and impact as a musical form. American sample-using hip-hop artists from this period inspired a generation of UK musicians and DJs to use samplers and copyrighted material to make music, and to be instrumental in establishing new dance music genres including big beat, breakbeat, and drum and bass. This article explores the sampling practice of these UK dance music producers. While the main focus here will be on copyright management and its influence on sampling practice, some consideration will also be given to other factors that have had significant bearing on these producers' approach to sampling, such as formative influences, aesthetic choices and some of the technical and creative restrictions particular to digital sampling. The methodological approach used has been that of a case study in the form of semistructured interviews, either in person or over the telephone with the participants. Robert Yin notes that "the case study's unique strength is its ability to deal with a full variety of evidence" (2003: 8), and the goal here is to provide some "analytic generalization" about sampling practice rather than to "enumerate frequencies (statistical generalization)" (ibid.: 10). Additionally, a review of UK and US copyright law and its enforcement is undertaken in so far as it relates to the way that the music industry in the UK deals with samples and sampling. The intention in this article is neither to champion a more liberal approach to copyright enforcement of digital sampling, nor to argue for reform of copyright law (see Kwetchsmer \& Kawohl 2004: 21-53). None of the producers interviewed here advocated an end to the clearance process for substantial samples, and this article is primarily concerned with the development of UK sampling practice, the industry's approach to sample clearance as mediated by current legal interpretation of copyright infringement, and the extent to which creative practice has changed in response to sample clearance practice. 
Much of the literature discussing digital sampling has focused on hip-hop in general and US hip-hop in particular. Tricia Rose (1994) explored hip-hop and sampling as expressions of African-American musical and cultural tradition, while Joseph Schloss's ethnographic study of US hip-hop producers sought to establish ethical rules for sampling practice (2002: 101-133) and aesthetic guidelines for hip-hop composition (ibid.: 135-168); Kembrew McLeod $(2002,2005)$ and McLeod and Peter Di Cola (2011) have explored the effect of increasingly stringent interpretation of copyright law in the US with regard to digital sampling and the knock-on effect for creative practice among hip-hop producers. Meanwhile, legal experts such as Mark Brodin (2005), Lucille M. Ponte (2006) and Amanda Webber (2007) have examined the current US interpretation of copyright infringement in connection with digital sampling, as established by judicial precedent, and offered arguments as to why it is to be found wanting, both in terms of the spirit and letter of statute, and in its recognition of the precedents set by prior rulings. They have also offered ideas for reform such as a revision of fair use and/or compulsory licensing to cover digital sampling.

Rather less has been written about sampling in a specific UK context. Timothy Warner (2003: 95-104) has explored the use and effect of sampling in the pop productions of Trevor Horn; Mark Katz (2004: 147-151) has offered an analysis of Fatboy Slim's "Praise You" (Skint 1998); and Paul Harkins (2010: 177-194) has discussed the influence of the vocal micro-sampling techniques of US garage producer Todd Edwards on the sound of UK garage.

While the track records of the interviewees quoted in this article do not necessarily validate their views, they do provide evidence that they have worked consistently within the music industry at a sufficiently professional level for their experiences of sample usage and clearance to be representative of industry practice, and for their immersion in the industry to have been over a sufficient time span for them to have experienced changes in the way in which the UK music industry has managed digital sampling. It is, therefore, considered helpful to provide a brief background on the contributors to this study:

a) Richard Barratt. Richard, better known as Parrot is a DJ and producer who formed Sweet Exorcist (Warp Records) with Richard Kirk (Cabaret Voltaire), was a member of Add $\mathrm{N}$ to $\mathrm{X}$ and part of the dance act All Seeing I who had top 20 hits in the UK with the songs "Beat Goes On" (FFRR 1998) and "Walk Like A Panther" (London Records 1999).

b) Andy Carthy. Better known as Mr Scruff, Andy is a DJ and producer who has released over thirty singles since 1995 and five albums for the Ninja Tune label, including a UK top 30 album in Trouser Jazz (Ninja Tune 2002). He is also very well known in the UK for playing five to six hour DJ sets, incorporating a wide range of dance music genres, at his touring club night "Keep It Unreal".

c) Aston Harvey has worked with artists including Rebel MC, Definition of Sound and DJ Rap. As part of Blapps Posse, he was responsible for the hit "Don't Hold Back" (Tribal Bass 1991), was a member of remix specialists The Sol Brothers and is best known as one half of The Freestylers, along with Matt Cantor, who have produced albums and singles that have reached the top 40 both in the UK and Australia.

d) Dean Honer, like Richard Barratt, was a member of Add $N$ to $X$ and All Seeing I, and as part of I Monster he created a UK top 20 hit with "Daydream In Blue" (Dharma Records 2003), which samples the song "Daydream" by The Günter Kallman Choir (Polydor 1970). This led to Honer's involvement in the production of "Daydreamin"' (Atlantic 2006) by US hip-hop star Lupe Fiasco, which sampled I Monster's record. Honer has also co-produced the 
Human League album Credo (Wall Of Sound 2011) and, with Barratt, has engaged in production work for Britney Spears.

e) Martin Reeves. Better known as Krafty Kuts, Martin is a well-known UK breakbeat producer and DJ with an extensive catalogue of over thirty of his own single releases, three studio albums, twelve mix albums and more than thirty remixes of other artists including Jurassic 5, Arthur Baker, Erik B \& Rakim, Africa Bambaataa and Fatboy Slim.

f) Saranne Reid. Managing director and founder of Sample Clearance Services in 1997, Saranne's client roster includes Lily Allen, Hot Chip, Fatboy Slim, Rihanna and numerous major and independent record companies and publishing companies.

\section{UK dance music sampling practice}

It should be acknowledged here that UK dance music covers a multiplicity of genres and that these interviewees' views cannot necessarily be seen to be representative of all of these genres, although the range of experience of the producers contributing to this study does include house, techno, early hardcore, breakbeat, big beat, dubstep, hip-hop and trip hop. For the sake of argument, then, references to "dance music" in this article will refer to music created in one or more of these genres, if not to all conceivable genres of UK dance music. The majority of my interviewees are indicative of the musical background of many of the participants in UK dance music production. As DJs, often with many years of experience of intensive listening to a broad spectrum of dance music, coupled with a practice-based understanding of the kind of combinations and dynamic shifts required to keep a dance floor full, these producers found that the digital sampler allowed them to transfer their skills and ideas to a permanently recorded medium, often without considering the legality or consequences of sampling, at least in the early days of their production histories. Richard Barratt says that as a DJ he was "obsessed with breakbeats, and collecting breakbeats and samples" and saw an opportunity to create his own music "out of these other people's drum loops, beats, bass lines, what-have-you, and it never really occurred to us that it was thievery or anything like that" (Barratt interview 2011). Aston Harvey reports a similar process of immersion in dance music from avidly collecting American hip-hop records to making music with his turntables "doing it proper hip-hop style with two copies of the same tune, and just scratching the beats in my bedroom" (Harvey interview 2011) to finding a studio with an early sampler and making his first records. Andy Carthy also acknowledges the influence of American hip-hop from the mid to late 1980s, commenting that for producers of his generation, "a lot of UK people, myself included, when they get a sampler, it's because they like the sound of Public Enemy or Pete Rock or whatever" (Reeves interview 2011). These DJ/producers applied the techniques they heard being used in American hip-hop records to their own productions, often drawing on similar genres for source material to those used by their formative influences, such as soul, jazz and funk. Where these UK producers depart from the their American counterparts is in their willingness to sample directly from hiphop records, compilations and/or reissues, practices which go against a number of the ethical rules established by Joseph Schloss in his ethnographic study of American hiphop, Making Beats (2004: 114-130). His American producer interviewees stressed the importance of finding previously unused samples on the original vinyl release because "crate digging" (hunting for obscure records) was seen to be an essential part of hiphop production practice. Another key difference to their American counterparts is the desire of these UK producers to re-imagine and re-purpose hip-hop, with its common tempo range of $85-105 \mathrm{BPM}$, into something more functional for a club environment, influenced by the late 1980 s/early 1990 s rave scene, where a tempo range of 120 140BPM was the norm: 
You know, the sound of original hip-hop was sampling...When I first started making music I was sampling hip-hop. I first started making music around ' 88 , ' 89 and [with] the first record I actually put out properly as my own, I was sampling hip-hop and funk records...Basically we were taking breaks from the Ultimate Breaks \& Beats compilations and sampling James Brown stabs and acapellas and hip-hop. [We were] putting it together with hip-hop records, but in a newer way and a more dance floor friendly way. (Harvey interview 2011.)

I was a hip-hop DJ and...I just needed some more up-tempo beats. I was going to early raves at the time and hearing...the [UK label] Shut Up \& Dance stuff and the early breakbeat sort of thing, like the early Prodigy stuff...It was kind of like this early form of instrumental hip-hop, but faster and it was better on the dance floor, like the big beat stuff in '95, '96, '97 and all the Fatboy Slim stuff, and there was something really special about it, and obviously l'd started collecting records, like ridiculous amounts, and I just wanted to use them for that purpose, and I wanted to make records...so I started wanting to make music with more up-tempo beats, like instrumental hip-hop. (Reeves interview 2011.)

While the interviewees acknowledge a debt to American hip-hop, they also note other influences and offer suggestions as to what may be distinct about a UK approach, including the treatment or staging of samples, and other musical influences that have a bearing on the sound:

Big beat at the time was massive, but what was good about it was it incorporated a lot of different flavors. You know - you'd go to a night of big beat and hear drum and bass, hiphop, funk, disco, house and break beat... They [UK producers] use a sample or a sound distinctly, loud in the mix. It's prominent and you recognise it, and as soon as you hear it, you cheer. It's there to be recognised, it's like "Yeah! Yeah! We found this idea, we found this sound, and we wanna show you." (Reeves interview 2011.)

I think reggae has always played a very important part in [UK] dance music throughout its history. Even in the acid house days a lot of tunes had a ska influence, and then the whole jungle scene came along, sampling the reggae stuff... The first super dance group, the Prodigy, all of their albums had samples... It's funny, there's no Americans that have really tried to do it. The Prodigy is an extremely English sound. It stems from the British rave scene I reckon... [discussing up-tempo club music] they're [the Americans] great at doing house music, but that's about it I think... breakbeat-wise, it's awful. (Harvey interview 2011.)

In summary, UK dance music producers' sampling practice draws heavily on that of the American hip-hop producers who made them aware of both turntablism and the possibilities of using samples to make records. UK sample-based dance music's homage to their US heroes extends to sampling them for their own productions, such as Krafty Kuts' "Gimme The Funk" (Southern Fried 1999) which samples "The Breaks" by Kurtis Blow (Mercury 1980), Fatboy Slim's "Rockafeller Skank" (Skint 1998) which samples "Vinyl Dog Vibe" by Vinyl Dogs feat. Lord Finesse (Vinyl Dog Records 1997) and "Smack My Bitch Up" by The Prodigy (XL Recordings 1997), which uses "Give The Drummer Some" by Ultramagnetic MC's (Plateau Records Inc. 1988). As noted by Schloss (2004: 114-119), it is unusual for US hip-hop artists to sample other hip-hop records, and UK sampling practice also differs in the tempo of the resulting music and its primary purpose as club music. Another difference is the lack of rappers in many of the productions. While Harvey's group The Freestylers have used MCs in their productions and some of Krafty Kuts' records also feature rappers, many big beat, breakbeat and house records do not feature a vocalist; instead, the sample is often foregrounded and provides the melodic and vocal (if the sample includes vocals) hook or hooks for the piece. This in turn means that a substantial piece of another record, often both in terms of length and significance, can be required, which leads to the question of how far sampling is permitted under UK law. 


\section{Legal \& industrial background}

The legislation governing digital sampling in the UK is the Copyright, Designs \& Patents Act 1988 (hereafter CDPA). There are two sets of rights for the sampling artist to negotiate, assuming that the sampling is of recorded music, namely the copyright of the musical work (the song or other musical composition) and the copyright of the sound recording. The songwriter (or songwriters), frequently also the performer or one of the performers in popular music, owns the copyright of the song or composition, but unless he or she self-publishes, he/she will have assigned this copyright to a music publishing company, generally referred to as the publisher. The publisher will take a percentage of a writer's income from their catalogue of compositions in return for collecting royalties on their behalf, and for finding additional ways to generate income from their music, such as synchronisation (placing them in films, television programmes or computer games) or covers (recordings of the material by other artists). The record company which released the original piece of music generally owns the recording copyright outright, although some smaller independent labels may share this copyright with the artist or even allow the artist to retain it (for a fuller discussion of UK record labels and publishers, please refer to (Harrison 2011)). In terms of the negotiation process, then, the sampling artist or his/her label needs to obtain permission to use a portion of the original sound recording, generally referred to as the master clearance, from the record label that owns it, and the permission from the writer(s) of the musical work (legally speaking, a combined musical and literary work if lyrics are present), the publishing clearance, to reproduce aspects of their composition by reaching agreement with the publisher.

The major record companies, or big three, Sony Music Entertainment, Warner Music Group and Universal Music Group all have their own publishing companies (Sony/ATV Music Publishing, Warner/Chappell Music and Universal Music Publishing Group respectively) and encourage artists or bands that they sign to be published in-house, although as far as the sampling artist is concerned this still necessitates, in all likelihood, two separate sample clearance negotiations because the major record companies and their publishing companies are distinct organisations. Smaller independent record labels often also have an in-house publishing company (Mr Scruff's label, Ninja Tune, for example, has a publishing arm for their artists called Just Isn't Music) and given their much smaller scale in comparison to the major companies, the sampling artist or their label is more likely to be involved in a single negotiation for both sets of rights. The sampling artist's record label will generally use a freelance specialist who will conduct negotiations on their behalf. A fee is normally required for the master clearance, while the publishing clearance will generally require the sampling artist to give up a percentage of their publishing in the new work, effectively making the writer of the sampled musical source a co-writer of the new work.

The size of the fee and the amount of publishing relinquished will depend on the popularity of the sampled record and the substantiality of what has been sampled. Under the terms of the CDPA, sampling without clearance is considered to be the theft of intellectual property, which means that in theory infringement can only occur if a "substantial part" (s.16(3) (a) CDPA) of the original work has been copied. There are no hard and fast rules, however, in UK law for what is meant by "substantial", because this could be determined either quantitatively and/or qualitatively in relation to the original work, but also in terms of the quantitative or qualitative significance of the sample in the new work. Ann Harrison comments that very few copyright disputes in the UK concerning sampling get as far as the courts because of the potential cost to a sampling artist's record label not only in legal costs, but in the accompanying injunction to cease production and/or seize existing copies of the record concerned (2011: 239243). Relevant cases that have got as far as the courts rarely fail to reach settlement prior to judgement, but Harrison notes the case of Hyperion Records Ltd v. Warner Music (UK) Ltd [1991] where British dance act The Beloved had sampled a seven note 
vocal phrase from "O Euchari" (Hyperion 1982), performed by Emily Van Evera, for their song "The Sun Rising" (WEA 1990). The judge in a preliminary hearing gave the view that eight seconds was not too short a sample to constitute a substantial part, but settlement between the parties was reached prior to a full hearing. In Produce Records Ltd v BMG Entertainment International UK \& Ireland Ltd [1999] (ibid.: 340) UK dance act The Farm's record label sued BMG for sampling a vocalisation made by their singer Paula David on "Higher and Higher" (Produce Records 1991) and using it repeatedly in the hit record "Macarena" by Los Del Rio (BMG 1996). Had this case not been settled out of court, it would have helped establish whether or not what Harrison describes as "the widely held view that 3 seconds is the minimum amount necessary to constitute a substantial part" (ibid.) had judicial support. Harrison also notes that the out of court settlement may well have been due to there being too much at stake by such a judicial precedent being set, because it would have prevented any record companies arguing from that point onward that samples of less than three seconds could not be considered substantial.

It can be seen, then, that in the UK neither sampling artists nor their record labels can rely on any legal precedent as to what kind of sample, either in quantity or quality, may be considered sufficiently substantial for its usage to be copyright infringement. The legal situation would suggest that sample users err on the side of caution and seek clearance if in doubt, and it would also be reasonable to conclude that the threat of a court action and/or injunction puts the original copyright holders in a very strong bargaining position. Richard Salmon suggests that a number of factors will be considered by rights holders in such negotiations, including "the notoriety of the original record, and prominence of the sampled work in the new record...the likelihood of commercial success [of the new record]...the status and marketing spend [of the sampling artist and their label respectively]" (2010: 176-177). However, on paper at least, sampling artists and their labels in the UK have more leeway to explore their craft than their counterparts in the USA. In the Court of Appeals ruling in the case of Bridgeport Music Inc. v. Dimension Films, a definitive legal precedent or "bright-line test...one that...adds clarity to what constitutes actionable infringement with regard to the digital sampling of copyrighted sound recordings" was set (Bridgeport 2004: 397). The sample in question was a section of solo guitar from the record "Get Off Your Ass \& Jam" (Westbound 1975) by Funkadelic in the track "100 Miles And Runnin" by NWA (Ruthless/Priority 1990). The original case had found in favour of NWA and their label, concluding that the use of the sample did not "rise to the level of a legally cognizable appropriation" (Bridgeport 2002: 841) because even a listener who was familiar with the work of Funkadelic would not be able to recognise the sample without being advised of its inclusion. However in coming to a different judgement, the Court of Appeals referred to the US Copyright Act 1971, which had been worded in such a way as to protect record companies from the economic threat of their records being bootlegged by giving them the exclusive right to reproduce them:

Section 114(b) provides that the "exclusive right of the owner of copyright in a sound recording under clause (2) of section 106 is limited to the right to prepare a derivative work in which the actual sounds fixed in the sound recording are rearranged, remixed, or otherwise altered in sequence or quality." In other words, a sound recording owner has the exclusive right to "sample" his own recording. No further proof of [infringement] ... is necessary than the fact that the producer of the record or the artist on the record intentionally sampled...It is a physical taking rather than an intellectual one. (Bridgeport 2004: 398.)

While this decision refers to the recording copyright rather than the copying of a musical idea that would be covered by the publishing copyright, it effectively affirms all sampling as copyright infringement in the USA, as long as the original copyright owner can prove that their recording has been sampled. In theory, artists and producers in the UK are in a stronger position than their American counterparts because UK law requires evidence that a substantial part of the original recording has been used, 
leaving open the possibility of sampling copyrighted work without resorting to clearance.

However, the UK as well as most European countries, along with the USA, Canada, Australia, New Zealand and much of Africa, Asia and South America, is a signatory to the Berne Convention. As David Laing (2004: 70-85) notes, one of the Berne Convention's provisions is that the copyright laws of signatory nations will apply to copyrighted material created by authors resident in other signatory nations. This may explain why the experiences and views of the interviewees that follow indicate a more cautious approach to sampling in many cases than UK law would appear to require. The other point to note with clearing samples is that the rights holder is never obliged to give clearance and can simply refuse permission if a satisfactory deal cannot be reached. Clearly, this puts rights holders in a very strong position when it comes to negotiations over fees for the master clearance, and the percentages of publishing rights to agree the publishing clearance.

\section{Sampling and sample clearance in practice}

There was a general consensus among the interviewees that the UK industry's approach to sampling in dance music had changed significantly since the late 1980s and early to mid-1990s when uncleared samples were commonly to be found in productions. Additionally, Saranne Reid identifies the rise in the popularity of genres such as big beat for reinvigorating the use of sampling among UK producers from 1998 onwards, which in turn led the industry to recognise the economic potential involved in managing the interests of rights holders:

When I first sent up my sample clearance company fifteen years ago [1997], it was at a time when people, particularly in UK dance music, didn't clear samples. There was almost an industry agreement that [sample clearance] was a mystery and people were just acknowledging each other [by sampling]. When I first approached record labels and major publishing companies, there was no one in-house to deal with sample clearances. You went to some licensing body, and they weren't even sure how it worked. There were really no set terms or agreements...no one had any idea what it was worth or how you analysed anything. Then it became very lucrative as lots and lots of people began to sample. I think once Norman's [Norman Cook, AKA Fatboy Slim, with You've Come A Long Way, Baby (Skint 1998)] album became very big, it set a genre of people starting sampling and then there were lots of hits, one after another with massive samples in... Now, if you approach any record label or any major publishing company, there will be a designated person within that company who will deal solely with samples and sample clearances...Years and years ago, the deals were very different. You could clear anything on a complete buy out [currently, additional clearance fees may be required if, for example, the composition featuring the sample is used on a TV advert or feature film]. (Reid interview 2012.)

Most of the interviewees were of the opinion that sample clearance should be sought, especially for significant or recognisable samples, but they also believed that costs had become prohibitive for the master clearance, while the demands for high percentages of the publishing rights in return for publishing clearance were considered to ignore the creative and compositional talent that has been applied to make the new record. If the publisher of the sampled record believes the sampling to be sufficiently substantial, then a condition of clearance can be for the new record to be treated as a cover version of the original. For example, Fatboy Slim (Norman Cook) reveals in an interview that his track "Going Out Of My Head" (Skint 1996) which samples a version of The Who's "I Can't Explain" by Yvonne Elliman (Purple Records 1973) "is considered a cover version of "I Can't Explain" and "he [Pete Townshend] gets all the money for it" (O'Connor 1998). Cook perhaps wasn't helped in his quest to get reasonable terms for clearance on this occasion by waiting until a year after the record was released and already a hit in America because "we thought we'd get away with it" (ibid.). This attitude to clearance perhaps also confirms Saranne Reid's view that the 
UK music industry began to control the use of samples more closely since 1998. Dean Honer reports a similar experience to Norman Cook, with "Daydream In Blue" (Dharma 2003) by I Monster being treated as cover version and resulting in the loss of all the publishing income. He explains his view of what would be reasonable for a sampling artist to expect in terms of a share of the composition:

I think certainly if someone sampled four bars of my music l'd expect something for it, but l'd also respect the contribution that was made over the top. For instance, with "Daydream in Blue" we didn't get any publishing on that, whereas we thought because we'd written new sets of lyrics and complete new parts we deserved some kind of cut on the publishing, but it weren't to be. (Honer interview 2011.)

Andy Carthy reports similar experiences of the demands of publishing rights holders:

You know, sometimes you don't even get to speak to the artist, especially [with] major record labels, I'm sure they're like "it's $80 \%$ minimum or we're not even bothering replying to your email" kind of thing...Generally people want far more than what I consider reasonable in terms of, if you've written a tune, you know the proportion of that person's music that you've included in your tune versus the amount of music that you've added to it I suppose. (Carthy interview 2011.)

Richard Barratt's report of losing only "15 or 20\%" (Barratt interview 2011) of publishing for the clearance of a sample in "Hustle To The Music" by Funky Worm (Fon Records 1988) is indicative of the extent to which the demands of publishers have increased, while Saranne Reid confirms that master clearance fees have risen considerably in the last ten years. Another factor in the cost of master clearance in the UK may be that the industry maintains a more hard line approach to its necessity than the CDPA would appear to require. Saranne Reid is adamant about the distinction between publishing clearance and master clearance:

On the recording side, even if you sample a second, we need to clear it. It's someone's master, and any element you use of that master is a copy of that master, so, you always have to clear that master and one second is as much of an infringement as twenty minutes - that's an infringement of copyright. On the publishing side of things, you have to be able to show that you've copied someone's skill and labour at such a substantial level that it becomes infringement. (Reid interview 2012.)

The CDPA does not make a distinction between copyright infringement of a recording or a musical work, as it states in either case that a "substantial part" of the original work has to be copied for infringement to occur. It would appear, then, that the UK industry takes its view on the legality of sampling from the interpretation of American copyright law provided in the Bridgeport judgement, where "No further proof of [infringement] ... is necessary than the fact that the producer of the record or the artist on the record intentionally sampled" (2004: 399). It can be argued that this is a pragmatic view that prevents artists and their labels from running into legal difficulties if their records are released in the USA, and obviates the need to seek additional clearances. It also suggests that the three second threshold for a sample to be considered substantial enough for copyright infringement as suggested by Harrison (2011: 340) is not the current industry norm. This strict view on master clearance may have contributed to rising costs in the UK. Martin Reeves' comment that "I haven't got a major record label supporting me, so unfortunately I'm not going to be able to afford to clear a ten/twenty grand [£10,000-£20,000] sample" (Reeves interview 2011) shows how far these fees have risen in the last fifteen years, because this is approximately ten times the fee reported by one interviewee for the clearance of a substantial sample in 1998.

It can be argued that there is a certain irony in the demands for the costs of master clearance having risen substantially over a period when the value of sound recording rights have decreased significantly due to the dramatic decline in sales of recorded music. Despite significant rises in digital music sales as consumers have moved from the purchase of vinyl and CDs to digital downloading, the International Federation of the Phonographic Industry (IFPI) has reported a fall of $31 \%$ in the value of the global 
recorded music industry between 2004 and 2010 (2011: 5). Richard Barratt notes that in the early $90 \mathrm{~s}$, even an underground record (one that is popular with club-goers without attracting mainstream radio play or appearing in the charts) "could sell thirty, forty, 50,000 records without even troubling the charts. It's a very different landscape today" (Barratt interview 2011). Saranne Reid echoes this thought, suggesting that the more financially straightened times in which the music industry finds itself have led to a more cautious approach to sample clearance:

Years ago, the dance market was huge and there was a lot of money flying around record companies and everyone else, there was much more money available and people taking risks [with sampling], but they don't take those risks any more. (Reid interview 2012.)

\section{Implications of clearance costs for sampling practice}

The interviewees generally report a more cautious approach towards sampling in the last five to six years; this coincides with the Bridgeport judgement effectively outlawing sampling without clearance in the USA. Although the evidence is circumstantial, the indication is that, at the very least, the major record companies have adopted a more hard-line approach to sample clearance in the wake of Bridgeport, regardless of the local laws governing the territory in which the sampling artist operates. Figures from industry bodies such as the IFPI and the PRS show that the economic landscape of the music industry is one where sales of recorded music have declined significantly while the value of publishing revenue, which garners royalties and licensing fees from the public performance and broadcast of music, has become ever more important in trying to make good on this revenue shortfall (Page \& Carey 2009: 3 ). At the same time, the qualitative interview data gathered here suggests that sample clearance costs have increased far above inflation, arguably because there is an increasing need for the UK music industry to exploit the commercial possibilities of its rights ownership as far as possible. This has led to very high percentages being required from sampling producers in their new compositions in return for publishing clearance, and it should also be noted that most UK dance music producers are signed to independent labels that do not have the financial resources of the major record companies to facilitate the clearance of substantial and well-known samples, as used by American producers such as $\mathrm{P}$ Diddy, Kanye West and Jay-Z. It is perhaps no surprise, then, that the majority of my interviewees have, out of economic necessity, modified their approach to sampling as a result:

I would definitely be more cautious. I've tried to use more obscure things rather than sampling something blatantly obvious like James Brown, Parliament, Funkadelic, Lynn Collins...because people are just going to come down on you really hard. When you sample a more obscure artist they're not going to want so much money when you clear the sample. (Reeves interview 2011.)

[I'm] a bit more cautious, yeah, because I've had instances where I've made tunes I'm really happy with and then not been able to use the sample...I think your ear almost attunes to that and goes "well I'm not going to take the hooky bit of that record, I'm going to take the really weird bit in the middle of the bass solo and loop it in a way so that the chord change happens in quite a dissonant way half way through the bar." (Carthy interview 2012.)

Aston Harvey has a different view to the other interviewees, but one that is still reflective of the current economic landscape of the music industry. For him, the decline in recorded sales of dance music has seen releases become more of a promotional tool for live shows and DJ sets, with the value of the income generated by many of the records being of an insufficient level for rights holders to pursue artists for infringement:

If the record is big then, yeah [you should get clearance for it] but for the amounts records are selling these days, it's not worth chasing someone up and trying to clear a sample... If the record is going to be big, a major record label comes in and says "this is going to be massive", then yes [we would seek clearance] but apart from that, no. There's no point. 
It's a whole performance trying to clear something and it puts back the release [date] of your record... just feel it's unnecessary really. (Harvey interview 2011.)

While Aston Harvey remains committed to sampling, other interviewees spoke about using samples as a source of inspiration without using the sample itself. Saranne Reid advises that the replaying of samples, where the master is not actually sampled but a specialist company recreates the sound and feel of a section of it as closely as possible, has become increasingly popular, and Martin Reeves confirms that he had had samples replayed on his last album in order to keep down costs, and that he would probably have to adopt the same approach on his next album. One notable UK sample replay company, Scorccio, boasts of having created over 500 replays of vocals and or music since 1996, so Reeves is clearly not alone in this approach. However, it is not just the large music companies who have had to rely increasingly on publishing revenue; with income from the sale of recorded music dwindling, many artists have also come to depend on publishing rights, in the form of publishing deal advances, broadcast royalties and synchronisation fees. Using samples means sharing these income streams with the writer(s) of any music sampled. In some cases, this has led our interviewees to move away altogether from using samples in their records. Dean Honer highlights his current approach, which is to use a sample as a starting point, but eventually replace it with his own recordings, and modify any melodic content sufficiently to avoid the need for publishing clearance:

You can find a part of an old sixties record that you really like and then use a loop of that as a start point and add to it and add to it and recreate it, but not recreate it exactly musically, but just use it as a source of inspiration, or for the feel and the rhythm, and then get rid of the sample. So hopefully you've changed it musically but maybe you've kept the tempo and the actual feel of the piece as well. We [have] definitely originated tracks from samples and then got rid of the samples but there's nothing you could spot as saying "that's a piece of music from that sample". It would generally just completely change and bear no relation whatsoever to the original sample. (Honer interview 2011.)

Andy Carthy articulates very clearly both the value of samples to his work, and the reasons why, unlike Martin Reeves, he would not look to have samples replayed:

I think replaying samples is kind of defeating the object really, you know. If I want to replay samples, l'll record myself playing, and just make a tune out of that, you know what I mean? ... Also half the attraction to me of samples is the kind of the bits in there that you don't really want as well. You know, the bits you try to get rid of with EQing and stuff, but there's always room noise... there might be, you know, a bass line which you're trying to filter out but you'll still get the top end harmonics coming through and things like that...you still have shadows of what you're trying to lose, even if you're trying to selectively remove something from a finished recording, which actually I really like...So I quite like the fact that you only have a limited amount of control over a sample. And that's half the fun of it because you're trying to put things together that were never meant to be together... I just like the idea of findings these things and using the excitement of hearing this element that I want to isolate and repeat, or use in another context, that is a starting point for another piece of music. (Carthy interview 2011.)

\section{Conclusion - affordances and constraints}

Andy Carthy has indicated that while sampling provides opportunities, part of the enjoyment of the creative process for him is in having to work with the inherent restrictions, such as the elements in a sample that you wouldn't necessarily chose to include. James Gibson (1966) explored the idea of affordances when considering the senses as perceptual systems, while Donald Norman emphasises the value of understanding affordances and constraints in the design of objects in order to make the intended usage of an item clear:

Consider a pair of scissors: even if you have never seen or used them before, you can see that the number of possible actions is limited. The holes are clearly there to put something into, and the only logical things that will fit are fingers. The holes are affordances: they allow the fingers to be inserted. The sizes of the holes provide 
constraints to limit the possible fingers: the big hole suggests several fingers, the small hole only one. The mapping between holes and fingers - the set of possible operations is suggested and constrained by the holes. Moreover, the operation is not sensitive to finger placement: if you use the wrong fingers, the scissors will still work. You can figure out the scissors because their operating parts are visible and the implications clear. The conceptual model is made obvious, and there is effective use of affordances and constraints. (Norman 1998: 12-13.)

James Mooney has applied Norman's idea to music making tools, but has added the concept of a "spectrum of affordance" (Mooney 2010: 145) where the possible uses of a musical tool can be placed on a scale from "easy" to "impossible" (ibid.: 146), or equally, from probable to highly improbable. For example, the design and default settings of a software sequencer program such as Cubase means that,

because it requires a small (but significant) effort to change these default settings, so it is slightly (but significantly) more difficult to use this framework to create music in a time signature other than $4 / 4$, or at a tempo other than 120 beats per minute, and it is more difficult still to create music that is not metrically rhythmical at all (ibid.: 147).

I propose that the concept of affordances and constraints is very helpful when examining sampling practice. There are the affordances and constraints inherent in sampling technology; an obvious example in the early digital samplers was the constraint of a limited amount of sampling time, which meant the producers had to use short samples. If loops were to be used, the producers developed a technique to reduce the amount of sampling time required, as described by Harvey when he states that "the first sampler that we used when we started going into a studio would record about 8 seconds, so everything that you had to put in from vinyl had to go in at 45 and plus 8 on the turntable" (Harvey interview 2011). This technique would require the sample to be played back at a lower pitch than the one at which it had been sampled, making the frequency distortion or aliasing inherent in early samplers apparent, while the quantization or bit rate of early models (eight or twelve bit) meant that the dynamic range of a vinyl record was not faithfully captured in the process, resulting in a very compressed sound in terms of dynamic range. Andy Carthy expresses both the affordances and constraints of this process with regard to an early sampler popular with many hip-hop pioneers, the Emu SP-12:

I like the SP because it's so limited it's quite difficult to work with, but it has a very very particular sound. It only has one swing setting - it's either straight sixteenths or like a $67 \%$ swing - that's it. It's only got ten seconds sampling time, it's twelve bit. Whenever you tune anything you hear a load of aliasing going on and it sounds great - it sounds like a lovely frosting on top of the sample. It's mono. Every tenth of a second has to be accounted for in the sampling time, you know what I mean? But the way that restriction pushes you - it makes you sample album tracks at forty-five so you have to slow them down just so you can get a one bar sample in there, which then explains why a lot of hiphop written on the SP1200 has that lovely sort of crusty aliasing going on, which is quite musical. It sounds like a bitcrusher but a hell of a lot nicer and warmer. Then, the restrictions also mean that you can't layer up loads of samples because then, because it's so crunchy, if you tried to run even two or three loops together, you'd have no dynamics because with that crunchiness and the pleasing distortion and stuff, the restrictions of the machine mean that you can have a beat and a loop and that's about it. You couldn't have two loops running because there's not enough sample time, but then it wouldn't sound good if you had two loops running because the definition isn't there. So it's kind of... the whole sound of that machine, its restrictions are a kind of blessing as well because if you had an hour's sampling time on it but you liked the crunchiness that came from sampling stuff quickly and slowing it down, you'd very quickly just be making a musical mush. (Carthy interview 2011.)

The constraints in this musical tool for Andy Carthy are as important as its affordances in the creative process. Donald Norman also talks about cultural constraints, "constraints [that] rely upon accepted cultural conventions, even if they do not affect the physical or semantic operation of the device" (1998: 85). This brings to 
mind the ethical and aesthetic rules established by Joseph Schloss for sampling practice among American hip-hop producers. The qualitative data from my interviews suggests that different local cultural affordances and constraints apply to UK dance music producers, such as the acceptability, even by a relatively underground artist, of taking a substantial sample and making it the basis for a record, and a willingness to sample both from hip-hop records and from records whose genres are not normally used as source material in hip-hop. Increasing costs of sample clearance and the financial demands of publishers to reach agreement for publishing clearance have introduced constraints to the amount of samples these producers are able to use and still derive economic benefit from their work. However, this in turn has become an affordance, as it has led some of them either to apply the techniques of sampling to their own recordings, or to take less significant or recognizable sections when they do sample in order to minimise the costs:

I recently bought a couple of early 70 s drum machines, like an old Maestro Rhythm King. I've just been playing that in, putting that through synthesizers, recording it in and then chopping it up afterwards, so you're kind of creating drum loops and drum sounds on the fly, then recording it in and chopping it into its components. (Honer interview 2011.)

So you know, more and more recently l've just been recording myself attempting to play drums, that kind of thing, almost making a little groove, and then sampling that... and not allow[ing] myself to go back and mess around with all the individual elements. In the same way as having a sample, you're imposing those restrictions upon yourself, and quite often it's the pushing up against those restrictions and dealing with music that is already completed and using that as the starting point for something else - it's those restrictions which I think really test and encourage your creativity...So yeah, you tend to take less obvious bits of records and obviously you hunt for more obscure records, or you chop something within an inch of its life so even you've forgotten what you sampled...The new cautious approach in itself becomes a limitation, but not necessarily a bad one. I probably choose less musical elements to sample [now] and probably add more of my own musical input on top of it. (Carthy interview 2011.)

The producers interviewed may feel that their creativity can be insufficiently rewarded by receiving either a small percentage or even no share of authorship in return for the compositional work that they add when working with samples. The majority have made adaptations to their practice as a result, with some interviewees acknowledging that there are positive creative possibilities afforded by the constraints inherent in current copyright management. They are not alone, however, in their view that they are often insufficiently rewarded for the compositions they create that incorporate samples. Lionel Bently, for example has expressed "a sense of unease" at the "mismatch between the tests copyright law uses to establish authorship, and the tests used to establish infringement" (2009: 191-192). Jason Toynbee advocates a reform of copyright law that acknowledges the "social nature of both authorship and the work" and recognizes the value of "versioning, repetition and quotation" (2004: 131). Meanwhile, producers such as Andy Carthy and Dean Honer, seeing a value in the constraints placed on musical creativity by incorporating samples, have found ways to continue sampling practice without infringing copyright. How far younger producers will use copyrighted samples in their productions remains to be seen and begs the question of whether or not the practices championed by the producers here have, or will, become obsolete. There is some evidence that sampling practice is not confined to these more experienced producers. In 2011, the audio-visual mash-up artist Swedemason recently had a top 40 UK hit with "Masterchef Synesthesia" (Shine TV Limited/Dental Records 2011) which heavily sampled the television programme of the same name, suggesting that the desire to re-work, re-imagine and reconfigure will continue to inform musical practice, in spite of the strictures imposed on these practices by copyright. 


\section{Acknowledgements}

I would like to thank all of the interviewees in this study for their time, patience and insight and Bob Davis, Phillip Mclntyre and David Moore for their advice and support in researching and writing this article.

\section{References}

\section{Bibliography}

Bridgeport Music, Inc. v. Dimension Films, 230 F. Supp. 2d 830 - Dist Court, MD Tennessee (2002). http://scholar.google.co.uk/scholar case?case $=10196107418922785917 \& q=$ bridgep ort+Music\&hl=en\&as sdt=2,5. Accessed: 3 Dec 2012.

Bridgeport Music, Inc. v. Dimension Films, 383 F. 3d 390 - Court of Appeals, $6^{\text {th }}$ Circuit (2004).

http://scholar.google.co.uk/scholar case?case $=12983069391855039236 \& \mathrm{q}=$ bridgep ort+music+vs+dimension+films\&hl=en\&as sdt=2,5. Accessed: 3 Dec 2012

Bently, Lionel (2009) Authorship of Popular Music in UK Copyright Law. Information, Communication \& Society 12 (2): 179-204.

Brodin, Matthew (2006) Bridgeport Music, Inc. v. Dimension Films: The Death of the Substantial Similarity Test in Digital Sampling Copyright Infringement Claims - The Sixth Circuit's Flawed Attempt at a Bright-Line Rule. Minnesota Journal of Law, Science and Technology 6 (2): 821-863.

Copyright Act of 1976,17 U.S.C. § 107. http://www.copyright.gov/title17/92chap1.html\#107. Accessed: 27 Apr 2011.

Copyright, Designs and Patents Act 1988. (c.48). London: HMSO.

Gibson, James (1966) The Senses Considered as Perceptual Systems. London: Unwin Bros.

Harkins, Paul (2010) Microsampling: From Akufen's Microhouse to Todd Edwards and the Sound of UK Garage. In Anne Danielson Ed. Musical Rhythm in the Age of Digital Reproduction. Farnham: Ashgate: 177-194.

Harrison, Ann (2011) Music: The Business. 5th Edition. London: Ebury Publishing.

Hyperion Records Ltd. v. Warner Music (UK) Ltd. (1999).

IFPI. (2011) Digital Music Report 2011. http://www.ifpi.org/content/section statistics/index.html. Accessed: 15 Apr 2012.

Katz, Mark. (2004) Capturing Sound: How Technology Has Changed Music. CA: University of California Press Berkley.

Kretschmer, Martin \& Kawohl, Friedmann (2004) The History and Philosophy of Copyright. In Simon Frith \& Lee Marshall Eds. Music and Copyright. 2nd Edition. Edinburgh: Edinburgh University Press: 21-53.

Laing, David (2004) Copyright, Politics And The Industry. In Simon Frith \& Lee Marshall Eds. Music and Copyright. 2nd Edition. Edinburgh: Edinburgh University Press: 7085.

McIntyre, Phillip and Morey, Justin (2010) "Working out the Split": Creative Collaboration and Assignation of Copyright across Differing Musical World. Journal on the Art of Record Production, Issue 5 (July 2011), http://arpjournal.com $/ 849 / \%$ e2\%80\%98working-out-the-split\%e $2 \% 80 \% 99$-creativecollaboration-and-assignation-of-copyright-across-differing-musical-worlds/. Accessed: 12 Apr 2012.

McLeod, Kembrew and DiCola Peter (2011) Creative License: The Law and Culture of Digital Sampling. Durham, NC: Duke University Press. 
McLeod, Kembrew (2005) Freedom of Expression ${ }^{\circledR}$ : Overzealous Copyright Bozos And Other Enemies Of Creativity. New York: Doubleday.

McLeod, Kembrew (2002) How Copyright Law Changed Hip hop. Stay Free Magazine 20. http://www.stayfreemagazine.org/archives/20/public enemy.html; Accessed: 27 Apr 2011.

Mooney, James (2010) Frameworks and Affordances: Understanding the Tools of Music-Making. Journal of Music, Technology and Education 3 (2-3): 141-154.

Norman, Donald (1998) The Design of Everyday Things. London: MIT Press.

O'Connor, Brian (1998) The Funk Soul Brother: As Fatboy Slim, UK DJ Norman Cook Leads the Big Beat Parade - And laughs All the Way to the Bank. DJ Times, 11 November, http://www. djtimes.com/original/djmag/nov98/fatboyslim.htm. Accessed: 16 Apr 2012.

Page, Will and Carey, Chris (2009) Adding up the Music Industry for 2008. Economic Insight 15, 20 July, http://www.prsformusic.com/creators/news/research/Documents/Will Page and Chris Carey (2009) Adding Up The Music Industry for 2008.pdf. Accessed: 5 Apr 2012.

Passman, Donald S. (2011) All You Need To Know About The Music Business. Fifth Edition. London: Penguin.

Ponte, Lucille M. (2006) The Emperor has no Clothes: how Digital Sampling Infringement Cases are Exposing Weaknesses in Traditional Copyright Law and the Need for Statutory Reform. American Business Law Journal 43 (3): 525-560.

Produce Records Limited v. BMG Entertainment International UK and Ireland Limited [1999].

Rose, Tricia. (1994) Black Noise: Rap Music and Black Culture in Contemporary America. Middletown CT: Wesleyan University Press.

Salmon, Richard. (2010) Sampling and Sound Recording Reproduction - Fair Use or Infringement? Entertainment Law Review 21 (5): 174-178.

Schloss, Joseph (2004) Making Beats: The Art of Sample-Based Hip-Hop. Middletown, CT: Wesleyan University Press.

Toynbee, Jason (2004) Musicians. In Simon Frith and Lee Marshall Eds. Music and Copyright. $2^{\text {nd }}$ edition. Edinburgh: Edinburgh University Press: 123-138.

Warner, Timothy (2003) Pop Music - Technology \& Creativity. Aldershot, Hants: Ashgate,

Webber, Amanda. (2007) Digital Sampling and the Legal Implications for its Use After Bridgeport. St. John's Journal of Legal Commentary 22: 373-415.

Yin, Robert (1989) Case Study Research: Design and Methods. Newbury Park CF: Sage.

\section{Interviews}

Barratt, Richard (2011) Discussion of Personal Sampling Practice. [transcribed telephone interview] (Personal Communication, 3rd November 2011).

Carthy, Andy (2011) Discussion of Personal Sampling Practice. [transcribed telephone interview] (Personal Communication, 24 November 2011).

Harvey, Aston (2011) Discussion of Personal Sampling Practice. [transcribed telephone interview] (Personal Communication, 29 September 2011).

Honer, Dean (2011) Discussion of Personal Sampling Practice. [transcribed interview in person] (Personal Communication, 15 September 2011).

Reeves, Martin (2011) Discussion of Personal Sampling Practice. [transcribed telephone interview] (Personal Communication, 21 October 2011).

Reid, Saranne (2012) Discussion of Sample Clearance. [transcribed telephone interview] (Personal Communication, 23. April 2012). 


\section{Discography}

All Seeing I, The. 1998. "Beat Goes On”, Single, FFRR, 09 March, UK.

All Seeing I, The. 1999. "Walk Like A Panther", Pickled Eggs \& Sherbet, London Records, 20 Sep, UK.

Beloved, The. 1990. "The Sun Rising", Happiness, WEA, UK.

Berry, Chuck. 1958. "Johnny B. Goode, Single, Chess, 31 March, USA.

Blapps Posse, The. 1991. "Don't Hold Back", Single, Tribal Bass Records, UK.

Blow, Kurtis. 1980. "The Breaks", Kurtis Blow, Mercury, 29 September, USA.

Elliman, Yvonne. 1973. "I Can't Explain”, Food OF Love, Purple Records, UK.

Farm, The. 1991, "Higher And Higher" on Spartacus, Produce Records, 30 April, UK.

Fatboy Slim. 1996. 'Going Out Of My Head”', You've Come A Long Way Baby, Skint, 16 September, UK.

Fatboy Slim. 1998, "Praise You”, You've Come A Long Way Baby, Skint, 19 October, UK.

Fatboy Slim. 1998, "The Rockafeller Skank", You've Come A Long Way Baby, Skint, 19 October, UK.

Funkadelic 1975. "Get Off Your Ass And Jam", Let's Take It To The Stage, Westbound, April, USA.

Funky Worm, The. 1988. "Hustle To The Music", Single, Fon, UK.

Günter Kallman Choir. The.1970. "Daydream", The Very Best of the Günter Kallman Choir, Polydor, UK.

Human League, The. 2011. Credo, Wall Of Sound, 21 March, UK.

I Monster. 2003. "Daydream In Blue", Neveroddoreven, Dharma Records, 21 July, UK.

Krafty Kuts. 1999. "Gimme The Funk", Single, Southern Fried, $1^{\text {st }}$ March, UK.

Los Del Rio. 1996. "Macarena" Single, BMG, UK.

Lupe Fiasco (Feat. Jill Scott). 2006. "Daydreamin", Lupe Fiasco's Food \& Liquor, Atlantic, 25 September, UK.

Mr Scruff. 2002. Trouser Jazz, Ninja Tune, September, UK.

NWA. 1990. "100Miles And Runnin" EP, Ruthless/Priority, 14 August, USA.

Prodigy, The. 1997. "Smack My Bitch Up", The Fat Of The Land, XL Recordings, 30 June, UK.

Swedemason. 2011. "Masterchef Synesthesia", Single, Shine TV Ltd./Dental Records, UK.

Ultramagnetic MC's. 1988. "Give The Drummer Some", Critical Beatdown, Next Plateau Records Inc., 4 October, USA.

Van Evera, Emily. 1982. "O Euchari”, A Feather On The Breath Of God, Hyperion, UK. 